\title{
El intérprete final de la Constitución: reflexiones desde la realidad boliviana actual
}

\author{
The Interpreter of the Constitution: \\ Reflections from current Bolivian Reality
}

\section{Boris Wilson ARIAS LóPEZ*}

RESUMEN: Desde que se tiene la noción de la separación de poderes u órganos de poder, el órgano legislativo se estructura y levanta desafiante frente al órgano judicial como queriendo dominarlo; sin embargo, la revitalización de las Constituciones ha provocado que los jueces no se constituyan en meros aplicadores de las leyes sino en controladores de la actividad legislativa, de ahí que se produce la pugna entre ambos órganos de poder por constituirse en el intérprete final de la Constitución, ya que ello permite la dominación de un órgano sobre otro, aspecto que es analizado en el presente trabajo que intenta mostrar cómo ambos órganos se encuentran en un contexto histórico y político que coadyuvará a determinar en definitiva el alcance de sus atribuciones.

Palabras clave: separación de poderes, Poder Judicial, Poder Legislativo, interpretación.
ABSTRACT: Since the notion of the separation of powers is structured the legislature stands defiant against the judiciary; however, the revitalization of the Constitutions made Judges are not subject to the law but to control the legislative activity. Produced the struggle between the two organs of power to be the "last" interpreter of the Constitution because it allows the domination of another organ of power, the present paper attempts to show how the two bodies are in a historical context that will contribute to determine ultimately the scope of its powers.

Keywords: Separation of Powers; the Judiciary; the Legislature; Interpretation.

* Abogado. Magister en derecho constitucional por la Universidad Andina Simón Bolívar. Docente investigador de la Universidad Mayor de San Andrés.borisito55@hot mail.com. 
SumARIO: I. Introducción. II. La separación de poderes y los dos modelos de órgano judicial. III. El intérprete final de la Constitución. IV. Bolivia y el diálogo institucional entre el Tribunal Constitucional Plurinacional y el órgano legislativo.

V. A modo de conclusión.

\section{INTRODUCCIÓN}

La separación de funciones referida por Aristóteles buscaba proteger la eficiencia del gobierno; ${ }^{1}$ luego, durante la Edad Media la división de poderes protegió a los estamentos — nobleza, clero y burguesía—, es decir, se resguardaba sus privilegios. Sólo a partir de la revolución burguesa se manejó la idea de controles recíprocos entre los órganos de poder constituido - Legislativo, Ejecutivo y Judicial — para resguardar los derechos.

Ahora bien, con respecto a la relación entre el órgano legislativo y el órgano judicial se tiene que las diferencias competenciales entre ambos órganos se pronunciaron luego de la segunda guerra mundial y la revalorización de las Constituciones, en la medida en la que el legislador pasó de ser defensor de los derechos convirtiéndose en una instancia que más bien amenazaba a los mismos al viabilizar en su momento la aprobación de normativa fascista o nacionalsocialista, pero además la constitucionalización de los derechos provocó se aumentara el poder interpretativo del órgano de control de constitucionalidad en desmedro de la del órgano legislativo, ${ }^{2}$ es decir, la protección de la libertad por la ley se modificó al paradigma de la protección contra la ley, mediante el control de constitucionalidad.

Sin embargo, de manera posterior muchas decisiones controversiales del órgano judicial y particularmente del Tribunal Constitucional, muestran a este órgano como un legislador positivo, ${ }^{3}$ lo que pone en duda la

1 Platón diferenciaba a: 1) los gobernantes cuya virtud era la sabiduría, 2) los guerreros o guardianes cuya virtud era el coraje, 3) los artesanos cuya virtud era la templanza.

2 Por ejemplo, la Constitución boliviana cuenta con 411 artículos de extensión regulatoria que deberían reducir la libertad configuradora de la Asamblea Legislativa Plurinacional y en contrapartida aumentar el control de constitucionalidad realizado por el Tribunal Constitucional Plurinacional.

3 Piénsese por ejemplo en las sentencias constitucionales atípicas —reductoras, aditivas, sustitutivas, etcétera- o en sentencias como la de Roe vs. Wade, 410 U.S. 113 (1973) de la Suprema Corte de los Estados Unidos de América que estableció la regla 
separación de poderes y ahonda los conflictos entre ambas instituciones que en el fondo podría resumirse en lo siguiente: si las competencias de los órganos de poder se definen en la norma suprema, entonces se tiene que quien se constituye en intérprete final de la Constitución es el que define las competencias del resto de los órganos de poder y las suyas propias, de ahí que la pugna entre los tribunales constitucionales y los parlamentos, en el fondo, no es otra que la de tener la última palabra respecto a la interpretación de la Constitución. ${ }^{4}$

Analizadas así las cosas, muchas son las ambivalencias que aquejan a las sociedades modernas, por ejemplo la histórica separación del rey y del Legislativo se tradujo en la contraposición del Ejecutivo frente al Parlamento; luego tenemos a las mayorías como gobierno frente a las minorías como oposición, y a la oposición entre el Legislativo de cara al Judicial y/o Tribunal Constitucional, última contraposición que se analiza en el presente trabajo en el contexto del constitucionalismo boliviano actual.

En este sentido, se procederá a realizar en los puntos II y III consideraciones generales sobre la temática, y en el punto IV se analizará cómo en Bolivia el Tribunal Constitucional Plurinacional considerado en la teoría y en la propia Constitución como la instancia de control de las leyes, es a su vez juzgado por realizar dicha labor por un órgano legislativo donde la mayoría pertenece a un solo partido político, lo que permite sostener que en los hechos hoy en día el juez constitucional es controlado justamente por el órgano al que tendría que controlar.

trimestral permitiendo a las mujeres a realizarse un aborto en los primeros tres meses de embarazo a partir del derecho a la intimidad y que a criterio de muchos críticos convirtió a dicho tribunal en un legislador positivo.

4 Recuerda Michel Rosenfeld que: “...en 1987 Edwin Meese, procurador general del presidente Reagan, argumentó que, aunque todos están obligados por la Constitución de los Estados Unidos, las decisiones de la Suprema Corte producían 'derecho constitucional' no vinculante para el presidente o el Congreso; desde el punto de vista de Meese, los últimos son intérpretes constitucionales tan auténticos como la Corte dado que las tres ramas del gobierno federal son iguales según la Constitución". Rosenfeld, Michel, "El juicio constitucional en Europa y los Estados Unidos: paradojas y contrastes", Revista Iberoamericana de Derecho Procesal Constitucional, México, núm. 8, julio-diciembre de 2007. 


\section{LA SEPARACIÓN DE PODERES Y LOS DOS MODELOS DE ÓRGANO JUDICIAL}

La traumática revolución francesa y la idea de un orden nuevo, trajo también la separación de poderes basada en la especialización de competencias, pero no en el control recíproco de los órganos de poder; así, el poder Legislativo y el Poder Ejecutivo no debían concentrarse, pues de lo contrario el gobernante podría desobedecerlas o hacer las competencias a su medida.

Para Montesquieu era claro que: “...es una experiencia eterna que todo hombre que tiene poder siente la inclinación de abusar de él...", ${ }^{5}$ de ahí que sea necesario controlar y distribuir el poder ${ }^{6}$ de forma que: "para que no se pueda abusar del poder es necesario que, por la disposición de las cosas, el poder frene al poder...", ${ }^{7}$ y en esa medida, en su criterio la separación de poderes se constituía en una garantía institucional a favor de los ciudadanos.

Pese a la referida teorización, en los hechos la separación de poderes en Francia se caracterizó por la ambigüedad, pues por una parte se consagró como principio político en el artículo 16 de la Declaración de los Derechos del Hombre y el Ciudadano de 1789, que establecía: “Toda sociedad en la cual no esté... determinada la separación de los poderes, carece de Constitución", pero al mismo tiempo, se estableció la prevalencia de la ley y por tanto del órgano legislativo sobre los otros órganos, al establecerse en su artículo 6o. que: "La ley es la expresión de la voluntad general", de ahí que Francia sustituyó el gobierno del monarca por el predominio del Parlamento, institución que tenía preeminencia respecto al resto de órganos de poder.

Por la división social del trabajo, jueces y legisladores tenían encargadas diferentes labores de forma que el órgano judicial no podía entrometerse con una de sus sentencias en el Legislativo, ni una ley podía dejar

\footnotetext{
5 Montesquieu, Charles, Del espíritu de las leyes, México, Porrúa, 2003, p. 143.

6 A decir de Peter Haberle: “Además, se debería aprovechar una parte de la sabiduría antropológica, que ofreció a Montesquieu en 1748 la oportunidad de descubrir la división de poderes: el ser humano, por naturaleza, se inclina hacia el abuso del poder. Y esto no vale tan sólo para el ser humano en cargos estatales o con responsabilidades públicas; también para el ciudadano que participa en el mercado". Haberle, Peter, "Siete tesis para una teoría constitucional del mercado", Revista de Derecho Constitucional Europeo, España, núm. 5, 2006, p. 17.
}

7 Montesquieu, Charles. Del espíritu de..., cit., p. 143. 
sin efecto una sentencia con calidad de cosa juzgada, ello en contraste a lo que sucedió en los Estados Unidos donde existía un modelo de pesos y contrapesos que permitía y alentaba más bien que un poder se entrometa e influya en otros poderes.

En este marco, el órgano judicial no tenía la posibilidad de reprochar una decisión del Parlamento, pues la legislación que recae sobre los ciudadanos emergía justamente de sus representantes que hacían la ley, por ello Montesquieu concibió al órgano judicial como un poder neutro a cuyos miembros no sólo les estaba vedado dejar sin efecto una ley, sino, que, ni siquiera podían interpretar la ley debiendo limitarse a aplicarla; así, sostuvo que: “...los jueces de la nación, como es sabido, no son ni más ni menos que la boca que pronuncia las palabras de la ley, seres inanimados que no pueden mitigar la fuerza y el rigor de la ley misma...", ${ }_{8}^{8}$ pues otro entendimiento hubiese hecho del órgano judicial un órgano de naturaleza política.

En cambio en los Estados Unidos de América, si bien el principio de separación de poderes tiene en primera instancia un componente organizacional, no sólo se buscó repartir competencias sino al mismo tiempo limitar a los órganos de poder de manera recíproca, para ello se utilizó al egoísmo humano, de manera que se esperaba que los diferentes actores se condujeran en defensa de sus propios intereses, de forma que un órgano de poder estuviera en posibilidades de neutralizar la acción de otro órgano de poder. ${ }^{9}$

En efecto, al igual que sucede cuando dos personas desconfiadas desean un pastel, para que el mismo se corte en tajadas iguales, pueden acordar que una corte el pastel pero que la otra elija primero, ello aseguraba en su criterio un reparto igualitario, en este sentido, la distribución del poder planteada por los constituyentes de Estados Unidos buscó contraponer esos intereses, por ejemplo, el órgano ejecutivo puede oponerse a la apro-

\footnotetext{
8 Ibidem, p. 151.

9 Los fundadores de los Estados Unidos de América partieron de la idea de que el hombre es egoísta y reverbera maldad, es decir, el diseño del control judicial es parte de un control a la maldad del ser humano más que a las competencias, por ello al ser los jueces seres humanos son al mismo tiempo seres malos y egoístas, de ahí que también deben estar limitados; así, James Madison, en El Federalista, núm. 51, sostuvo: "La ambición debe ponerse en juego para contrarrestar la ambición... Si los hombres fueren ángeles, el gobierno no sería necesario. Si los ángeles gobernaran a los hombres, saldrían sobrando lo mismo las contralorías externas que las internas del gobierno".
} 
bación de una ley mediante el veto presidencial, pero a la vez el propio funcionamiento del órgano ejecutivo está condicionado a los recursos económicos aprobados por el Legislativo.

Por otra parte y a diferencia de lo sucedido en Francia, no se confiaba ciegamente en las decisiones del Congreso, ${ }^{10}$ de ahí que en contraposición al órgano judicial francés, configurado como un poder nulo, se estableció el diseño contramayoritario del órgano judicial americano, el cual podía inaplicar leyes inconstitucionales y dictar sentencias impopulares, ${ }^{11}$ para ello se garantizaba a los jueces inamovilidad laboral e intangibilidad de sus salarios, de esta manera se buscó protegerlos y alejarlos del apasionamiento del debate público. ${ }^{12}$ Sin embargo, la facultad del órgano judicial de inaplicar una ley, emergente de un órgano de poder representativo de la voluntad popular - como lo es el órgano legislativo- provocó que en dicho país, se observe la actividad jurisdiccional como contramayoritaria; así, Bickel sostuvo al respecto que:

... cuando la Corte Suprema declara inconstitucional un acto legislativo frustra la voluntad de los representantes de las personas aquí y ahora, ejerce el control, no en representación de la mayoría prevaleciente, sino en su contra... es lo que realmente ocurre... es la razón por la que se puede acusar al control judicial de constitucionalidad como antidemocrático... ${ }^{13}$

Los referidos modelos de separación de poderes funcionaron de mejor o peor manera en las realidades donde se generaron, debido a que al volverse prestigiosos fueron imitados por otros países como el boliviano, sin

10 Debe recordarse que la independencia de las colonias americanas se originó en su lucha por obtener representación en el Parlamento inglés, la cual les fue negada y provocó la guerra de la independencia.

11 Se critica a esta postura que los fundadores en los Estados Unidos se: “orientaron a 'impedir la tiranía' de un sector de la sociedad sobre otros, más que a promover el diálogo y la cooperación entre tales sectores...". Gargarella, Roberto, "La democracia deliberativa en el análisis del sistema representativo: algunas notas teóricas y una mirada sobre el caso de la Argentina", Revista Sociedad, Argentina, vol. 6, 1995, pp. 77-94.

12 En este sentido, en el núm. 49 de El Federalista se sostuvo respecto a los jueces y sus cargos que: “...por el modo de su nombramiento, tanto como por la naturaleza y permanencia [de los jueces en sus cargos, ellos estarán] demasiado lejos del pueblo para participar de sus simpatías...".

13 Bickel, Alexander, The Least Dangerous Branch: The Supreme Court at the Bar of Politics, Estados Unidos, Universidad de California, 1962, p. 16. 
embargo, no necesariamente el trasplante implicó que se haya alcanzado el mismo resultado, ello porque en general al no poderse importar el contexto cultural y político de los países donde se generaron los referidos modelos, era inevitable se tuvieran resultados distintos.

\section{EL INTÉRPRETE FINAL DE LA CONSTITUCIÓN}

En primera instancia, el órgano legislativo reclamó el poder de interpretar la Constitución a partir de la función legislativa que debe cumplir, pues para ello necesariamente requiere interpretar la norma suprema, ${ }^{14}$ pero a través de la denominada interpretación auténtica que en general es aquella que proviene del mismo autor del precepto, ${ }^{15}$ también reclamó la interpretación final de la Constitución.

En este sentido, el reconocimiento al órgano legislativo de emitir leyes interpretativas implica que las mismas sean obligatorias al órgano judicial, pero quita el efecto vinculante a las sentencias en la medida en la que ante una interpretación incómoda del órgano judicial, el legislativo podría modificarla con una ley interpretativa que además tendría efecto retroactivo.

Por su parte, Kelsen identifica a la interpretación auténtica, no como aquella que deviene de la autoridad que hizo la norma, sino a aquella interpretación que proviene del órgano con facultad de aplicar la Constitución, lo que obviamente es gradual, ${ }^{16}$ es decir, el órgano legislativo a tiempo de

14 A decir de Néstor Pedro Sagués: "Nadie niega que el Poder Legislativo puede y debe ser intérprete de la Constitución. Es uno de los operadores constitucionales por excelencia, ya que si le toca dictar leyes, debe hacerlo conforme a las directrices de forma y de contenido que dispone la Constitución; y para eso, obviamente, tiene que interpretarla", Sagüés, Néstor Pedro, "El Congreso vs. el Tribunal Constitucional. La interpretación final de la Constitución", Revista del Foro Constitucional Iberoamericano, España, núm. 1, 2003, p. 312 .

15 El artículo 234 de la Constitución boliviana de 1967, abrogada, establecía: "Es facultad del Congreso dictar leyes interpretativas de la Constitución. Estas leyes requieren dos tercios de votos para su aprobación y no pueden ser vetadas por el presidente de la República".

16 Myrna Elia García Barrera señaló: “La interpretación auténtica es concebida por Kelsen como el procedimiento espiritual que acompaña al proceso de aplicación del derecho, en su tránsito de una grada superior a otra inferior, por lo que el juez debe presentar sus decisiones como procedentes del sistema jurídico preexistente (su fin no es innovar el sistema), y es en este contexto en el que cobra pleno sentido la exigencia de que los jueces motiven sus decisiones en el propio sistema jurídico", García Barrera, Myrna Elia, "La 
hacer una ley debe interpretar la norma constitucional, posteriormente el órgano ejecutivo tiene competencia para reglamentar la ley, para lo cual la interpreta pero a su vez interpreta a la Constitución, para finalmente llegar al nivel del órgano judicial que en la medida en la que es la última instancia en aplicar la norma constitucional, no sólo se constituye en intérprete auténtico en el ámbito de sus competencias, sino que para este autor también en el último intérprete.

En este contexto, tenemos que cuando el órgano legislativo se constituye en un poder constituyente-constituido, es decir, que tiene el poder de sancionar la Constitución y por tanto el poder de reformarla, entonces se entiende que también tiene el poder de interpretarla, ${ }^{17}$ de lo contrario el legislador ordinario sólo podría limitarse a emitir leyes interpretativas de otras leyes pero de ninguna manera de la norma constitucional.

Al respecto, en Bolivia — en teoría — debería rechazarse la facultad del órgano legislativo para emitir leyes interpretativas en la medida en la que:

- El propósito del control de constitucionalidad se dirige fundamentalmente a restringir y controlar al órgano legislativo, por eso el Legislativo no puede constituirse en la última instancia interpretativa de la Constitución, ello porque a decir de K. Loeweinstein: "los conejos no son generalmente los guardianes más seguros del jardín". ${ }^{18}$

- Cuando una Constitución entrega el control de constitucionalidad a un Tribunal Constitucional, éste llega a constituirse en el intérprete final de la norma suprema en la medida en la que puede declarar inconstitucional una ley interpretativa, ${ }^{19}$ por ejemplo

jurisprudencia y la interpretación en la teoría jurídica contemporánea y posmoderna", Letras Jurídicas, México, núm. 4, abril de 2007, p. 20.

17 Para Néstor Pedro Sagüés: "si la Constitución no otorga específicamente al Congreso competencias para interpretar por medio de ley o decreto a la Constitución con resultado vinculante, el eventual dictado de una 'ley interpretativa' de la Constitución, o norma análoga, solamente equivaldría a un pronunciamiento de ese Cuerpo, que no compromete ni obliga a los demás sujetos y operadores del sistema constitucional, ni mengua en lo más mínimo las competencias de revisión de constitucionalidad de los órganos que ejercen tal misión". Sagüés, Néstor Pedro, "El Congreso vs. el Tribunal Constitucional. La interpretación final de la Constitución”, cit., p. 316.

18 Loeweinstein, Karl, Teoría de la Constitución, España, Ariel, 1970, p. 617.

19 La interpretación del órgano legislativo es política, no le es vinculante al Tribunal Constitucional, es decir que si se emitiera una ley interpretativa pero se considerara por 
cuando a título de interpretación se pretende reformar la norma fundamental. ${ }^{20}$

- La facultad que tiene el Tribunal Constitucional para conocer las consultas sobre la constitucionalidad de proyectos de leyes del órgano legislativo implica que las sentencias constitucionales y, por tanto, las interpretaciones que contienen éstas, son vinculantes al legislador, de lo contrario, no tendría sentido la consulta.

En mi opinión, para determinar al intérprete final de la Constitución, deben tomarse en cuenta dos criterios: 1) la facultad configuradora del órgano legislativo, y 2) el diálogo institucional entre el Tribunal Constitucional y el órgano legislativo.

En este sentido, respecto al primer criterio, y para abordar la facultad configuradora del órgano legislativo debe considerarse las diferencias básicas de las actividades y competencias de ambos órganos, a saber:

- La ley es un acto de voluntad, mientras que la sentencia constitucional es un acto de conocimiento de la Constitución, ello explica por qué un Tribunal Constitucional puede dejar sin efecto una decisión del Legislativo, ya que en el fondo la Constitución es superior a una ley, pero además explica por qué el órgano legislativo no requiere fundamentar y motivar las leyes como lo hace el juez al emitir sus fallos, incluso se halle en minoría en un tribunal a través de votos disidentes que expliquen su posición. ${ }^{21}$

una minoría parlamentaria que esa interpretación es inconstitucional, entonces el órgano de control de constitucionalidad estaría habilitado para resolver dicha controversia.

20 Al respecto Miguel Mur Valdivia dice: "El simple empleo de fórmulas como "interprétese", "aclárese", "precísase" y cualquier otra expresión similar no es ni debe ser suficiente para que una norma se califique como interpretativa, pues cualquier institución jurídica se define principalmente en razón de su contenido y los conceptos que establece, y no de la denominación que se le asigne o de los términos empleados", Mur Valdivia, Miguel, "Elementos para la interpretación de las normas tributarias", Revista del Instituto Peruano de Derecho Tributario, Perú, núm. 23, p 58.

21 Para Arthur Kaufmann: "como quiera que existen: el lenguaje del legislador, lacónico por excelencia, carece de cualquier accesorio que adorne, no dice ni una palabra que sobre, simplemente ordena, nada más. El lenguaje del juez que, en contraste con el anterior, es más rico en expresión, es más concreto que el lenguaje de la ley, no renuncia a elementos de persuasión; el juez no desea sólo ordenar, como lo hace el legislador, también desea convencer", Kaufmann, Arthur, Filosofia del derecho, Bogotá, Universidad Externado de Colombia, 2002, p. 223. 
- Para ser legislador se requiere participar en un proceso electoral; en cambio, un juez ingresa a la carrera judicial por concurso público de méritos y examen de competencia, estándole vedado formar parte de un partido político. Dichas exigencias devienen de las competencias diferentes que tienen, la de representación y agregación de intereses por el Legislativo al hacer una ley, y la de control de la constitucionalidad respecto al Tribunal Constitucional.

- La interpretación del Legislativo no le vincula a decisiones futuras, es decir, hoy puede decidir que se elabore un código procesal penal regido por el principio de oralidad y mañana hacer otro código en el cual los actuados procesales sean escritos, lo que no sucede con el Judicial, donde los jueces están vinculados a sus decisiones anteriores.

- Incluso cuando el Tribunal Constitucional actúa como legislador negativo su actividad es claramente diferenciable de la del legislador, pues para este último una derogación constituye una "potestad"; en cambio, para el órgano de control de constitucionalidad la declaratoria de inconstitucionalidad derogatoria le es una "obligación"; mientras que el Legislativo busca permitir el cambio legislativo, la interpretación del órgano judicial busca evitar el cambio legislativo irregular, es decir, uno interpreta para aplicar la Constitución y el otro para evitar que el Legislativo vaya contra la Constitución.

A partir de dichas diferencias puede extraerse que la libertad configuradora del órgano legislativo implica una competencia delegada por la Constitución para determinar de acuerdo con la coyuntura política, social, económica, los medios para alcanzar los fines establecidos por la Constitución.

Así, cuando la Constitución boliviana de 1967 establecía en su artículo 132 que: "La organización económica debe responder esencialmente a principios de justicia social que tiendan a asegurar para todos los habitantes, una existencia digna del ser humano", ello implicaba que el órgano legislativo en ese marco constitucional debía elegir los mecanismos más apropiados para lograr dicha finalidad, los cuales podían inclinarse hacia una economía de libre mercado, estatizada o de economía mixta, lo que dependería de si el gobierno de turno era izquierdista o de derecha, debiéndose limitar el control de constitucional a determinar si esas medidas 
se encuentran o no entre las opciones interpretativas posibles de la Constitución.

En efecto, se reitera que la interpretación de la Constitución que hace el órgano legislativo no es definitiva, pues se basa en aspectos políticos, en cambio la interpretación que de la Constitución realiza el Tribunal Constitucional es definitiva, ${ }^{22}$ por ello el Legislativo por una conveniencia coyuntural, puede determinar que un código se rija por el principio de escritura y luego modificar la norma y establecer que se rija por el de oralidad, pero si el órgano de control de constitucionalidad establece que se rija por la oralidad o el de escritura, para modificar dicho criterio necesariamente se debe reformar la Constitución. ${ }^{23}$

Por ello y para evitar que el control de constitucionalidad se desborde, es decir, que la actividad jurisdiccional no desconozca el principio democrático por el cual los ciudadanos deciden a través de sus representantes y que a la vez tampoco invada las competencias del Legislativo, se establecen respecto a las demandas de inconstitucionalidad requisitos de admisibilidad y la prohibición de actuación de oficio del Tribunal Constitucional, supuestos que en este contexto buscan proteger la libertad configuradora que le corresponde al órgano legislativo.

22 El artículo 203 de la Constitución boliviana establece: "Las decisiones y sentencias del Tribunal Constitucional Plurinacional son de carácter vinculante y de cumplimiento obligatorio, y contra ellas no cabe recurso ordinario ulterior alguno".

23 "La cuestión es puramente institucional en último término: la administración tiene institucionalmente prefijada su línea de actuación, el legislador no. Por tanto, el control de los conceptos jurídicos indeterminados por los tribunales ordinarios en total (control mientras que no lo es, más que en la zona de certeza del concepto, el control del legislador por la justicia constitucional. Las zonas de penumbra pueden ser competencia del legislador ordinario, y no del juez constitucional. Esta explica la tensión constante entre la jurisdicción constitucional y los parlamentos: aunque a priori el TC sólo defiende la zona de certeza de los conceptos jurídicos indeterminados (siendo la zona de penumbra regulable por el legislador ordinario), paradójicamente es al primero a quien corresponde delimitar dónde se traza la línea. Tiene autoridad para hacerlo, pero siempre que al pluralismo le quede opción (zona de penumbra donde actuar las operaciones legítimas y zona de certeza negativa)... La prueba de que el pluralismo puede quedar anulado por una continua expansión de las zonas de certeza del concepto hasta que los constituyentes (y el propio texto en el fondo) entendían que era zona de penumbra del poder constituido está en las reacciones doctrinales ante las definiciones excesivamente detalladas de los conceptos", Alonso, Enrique, La interpretación constitucional, España, Centro de Estudios constitucionales, 1984, p. 121. 
Por otra parte, respecto al segundo criterio, el determinar quién es el intérprete final de la Constitución en relación al diálogo institucional entre el Tribunal Constitucional y el órgano legislativo, responde a las relaciones de poder y al diseño constitucional normativo.

Una crisis del sistema de partidos emergente de la falta de control de los votantes sobre sus representantes, la priorización de ambiciones personales y partidarias sobre el interés colectivo, la corrupción, el sometimiento del Legislativo al Ejecutivo, la falta de participación real de la ciudadanía en el procedimiento legislativo, entre otros, han traído como consecuencia la crisis de la representación parlamentaria, ${ }^{24}$ y por tanto el desprestigio de los parlamentos, lo que a su vez puede provocar el crecimiento de la facultad interpretativa y por ende del poder de los tribunales constitucionales, el cual es inversamente proporcional al decaimiento de la credibilidad de los parlamentos, es decir, si un Parlamento no es representativo le otorga la oportunidad al órgano de control de constitucional que sí lo sea.

Entonces, en la competencia por constituirse en el intérprete final de la Constitución, se tiene que si el Parlamento trabaja representativaente, el Tribunal Constitucional se deslegitimará si es activista, pero si el Legislativo está desacreditado, las sentencias constitucionales se prestigiarán y obtendrán apoyo del público, ${ }^{25}$ de forma que la colectividad se constituirá en el último juzgador de la rectitud de las decisiones judiciales y legislativas, porque si una sentencia constitucional sobre un tema controvertido como el aborto, la eutanasia, el matrimonio de personas del mismo sexo, etcétera, a criterio del público está equivocada, entonces será criticada, ${ }^{26}$ y a largo plazo perderá su efecto devolviendo al Parlamento su posición de dominio; o por el contrario, si se mantiene puede inclusive modificar

24 En Bolivia a los parlamentarios que no debaten y toman una posición grupal se los llama "levanta manos".

25 No debe verse el efecto inmediato de una sentencia sino a largo plazo; así, la sentencia del caso Brown contra Consejo de Educación de Topeka, 347 U.S. 483 (1954) de la Suprema Corte de Estados Unidos de América fue rechazada por estados sureños, pero luego de varios años la misma fue gradualmente aceptada prestigiando a la Corte y desprestigiando al mismo tiempo a sus detractores.

26 El Tribunal Constitucional peruano en la sentencia 2005-2009-PA, ante la incertidumbre respecto a si la "pastilla del día después" tiene o no efecto abortivo, prohibió su distribución gratuita, pese a ello autorizó su venta por farmacia privadas, lo que le generó diferentes críticas por presentarse la decisión como contradictoria, ello a lo largo del tiempo no sólo debilita el prestigio del órgano de control de constitucionalidad, sino también el cumplimiento de la decisión a largo plazo. 
el criterio mayoritario sobre una determinada temática, al mismo tiempo prestigiar al órgano de control de constitucionalidad frente al órgano legislativo, es decir, que en dicha competencia, al confundirse el elemento político con el jurídico las sentencias constitucionales ya no cierran el debate democrático sino que más bien lo abren, constituyéndose en un elemento más del debate, de forma que ni el Legislativo, ni el Ejecutivo querrán contraponerse o atacar una decisión del Tribunal Constitucional que a largo plazo sea considerada justa, pues caerían en impopularidad, en cambio, si dicha decisión jurisdiccional está equivocada, un ataque en su contra sin duda mejorará su popularidad, de ahí que todo dependerá de la prudencia de los magistrados ${ }^{27}$ y del contexto político en el que se tome una decisión.

En los Estados Unidos de América, en 1857 se emitió la sentencia "Dred Scott" ${ }^{28}$ que entendió que las personas de color jamás podrían ser consideradas ciudadanas y declaró inconstitucionales las leyes que permitían que un esclavo que se escapaba de un estado esclavista a uno que prohibía la esclavitud obtuviera su libertad, pues a su criterio, el gobierno no puede privar a los ciudadanos de sus propiedades sin un debido proceso, esta decisión provocó una cruenta guerra civil y luego la reforma a la Constitución eliminando la esclavitud. ${ }^{29}$ Posteriormente, a raíz de una interpretación de la Corte Suprema de Justicia que permitía la segregación de los ciudadanos por el color de su piel, ${ }^{30}$ en 1954 se emitió la sentencia "Brown", ${ }^{31}$ que declaró inconstitucionales las leyes que sustentaban la segregación racial en las escuelas, pues a criterio de los magistrados la separación generaba un sentimiento de inferioridad de las personas de color respecto a las personas blancas, lo que entonces provocó que el órgano de control de constitucionalidad de aquel país dictara diferentes sentencias

27 Si bien en los Estados Unidos de América existe el debate respecto al órgano judicial como contramayoritario, debe considerarse que dicho órgano a través de su jurisprudencia estableció las llamadas "cuestiones políticas" que refieren a decisiones o espacios constitucionales no controlados por el órgano judicial y que corresponden de manera exclusiva al legislativo o al ejecutivo dependiendo el caso.

28 Dred Scott vs. Sandford, 60 U.S. 393 (1857).

29 La enmienda XIII de la Constitución de los Estados Unidos de América de 6 de diciembre de 1865 sostiene: "Ni en los Estados Unidos ni en ningún lugar sujeto a su jurisdicción habrá esclavitud ni trabajo forzado, excepto como castigo de un delito del que el responsable haya quedado debidamente convicto".

30 Plessy vs. Ferguson, 163 U.S. 537 (1896).

31 Brown contra Consejo de Educación de Topeka, 347 U.S. 483 (1954). 
contra la segregación en diferentes estados renuentes, ${ }^{32}$ lo que a su vez se tradujo en legislación específica en la materia que tras concretarse permitió a la Corte concentrarse en otras temáticas.

La primera de las referidas sentencias es considerada una de las más oprobiosas en la historia de la humanidad, la otra en cambio una de las más prestigiosas. En ambos casos, las decisiones jurisdiccionales provocaron una reacción legislativa, una en contra de la Corte y otra a su favor, ${ }^{33}$ lo que nos muestra cómo la amplitud del control de constitucionalidad y el poder de los jueces dependerá en concreto del contexto histórico, social, económico, político, etcétera.

Entonces, los diseños constitucionales para proteger al ciudadano frente al Estado utilizan al propio Estado, es así como se explica por ejemplo que un solo ciudadano acudiendo a un tribunal constitucional $\mathrm{u}$ órgano judicial pueda provocar que una ley aprobada con una abrumadora mayoría parlamentaria sea declarada inconstitucional; sin embargo, también debe recordarse que los tribunales no son sólo defensores de la Constitución sino también de la ley que desarrolla la Constitución -v. gr. en amparos constitucionales - , por lo que no necesariamente tiene que existir una contraposición entre jueces y legisladores, y por ello mismo, lo deseable es que los tribunales a través de sus decisiones en esencia estimulen a los legislativos a ejercer sus competencias y no pretendan sustituirlos. ${ }^{34}$

Consecuentemente, el intérprete final de la Constitución se determina siempre en el caso concreto tomando en cuenta el contexto concreto en el que se desenvuelve la dinámica política y de acuerdo con la solidez institucional de los órganos tanto legislativo como judicial, aspecto del cual no puede eludirse tampoco el constitucionalismo boliviano, lo cual nos lleva al siguiente punto.

32 Piénsese en el caso de Ruby Bridges Hall que en Nueva Orleáns, Louisiana, en 1960 a sus seis años fue la primera persona de color en un colegio de blancos, a quien tuvo que custodiarse por agentes federales.

33 Debe recordarse como otro ejemplo respecto a la relación entre Judicial y Legislativo que la respuesta a la sentencia Pollock vs. Farmer's Loan \& Trust Co, 158 US 601 (1895) que sostuvo que el impuesto sobre la renta era inconstitucional provocó se gestionara la Enmienda XVI a la Constitución de los Estados Unidos de América que admitía dicho impuesto.

34 A decir de Bellamy: "En otras palabras, que es la forma democrática de gobierno, y no un marco legal, la que ofrece el mecanismo más apropiado para limitar el poder político", Bellamy, Richard, Constitucionalismo político: una defensa republicana de la constitucionalidad de la democracia, España, Marcial Pons, 2010, p. 176. 


\section{Bolivia Y EL DiÁlogo INSTITUCIONAL ENTRE EL TRIBUNAL Constitucional Plurinacional Y EL ÓRGano LEGISLATIVO}

La Constitución boliviana otorgó un notorio poder de dominio al órgano legislativo respecto al Tribunal Constitucional Plurinacional, lo que puede evidenciarse en su artículo 159.11 que establece como atribución de la Cámara de Diputados: “Acusar ante la Cámara de Senadores a los miembros del Tribunal Constitucional Plurinacional... por delitos cometidos en el ejercicio de sus funciones", concordante con el artículo 160.6 de la norma suprema que entrega como competencia a la Cámara de Senadores: “juzgar en única instancia a los miembros del Tribunal Constitucional Plurinacional... por delitos cometidos en el ejercicio de sus funciones, cuya sentencia será aprobada por al menos dos tercios de los miembros presentes, de acuerdo con la ley", ${ }^{35}$ de manera que ante una diferencia interpretativa entre ambos deja la posibilidad de que el órgano legislativo pueda juzgar a los miembros del órgano de control de constitucionalidad. ${ }^{36}$

Sobre dicha facultad, se ha observado que este juicio político podría implicar una afectación significativa al principio de separación de poderes y control recíproco, ${ }^{37}$ pues es el mismo órgano controlado el que podría luego controlar la decisión del órgano que efectúa el control de constitu-

35 La Ley 612 de 3 de diciembre de 2014 que modifica la Ley 044 de 8 de octubre correspondiente a la "Ley para el juzgamiento de la presidenta o presidente y/o de la vicepresidenta o vicepresidente, de altas autoridades del Tribunal Supremo de Justicia, Tribunal Agroambiental, Consejo de la Magistratura, Tribunal Constitucional Plurinacional y del Ministerio Público" sostiene: "La función de juzgamiento de la Asamblea Legislativa Plurinacional, tiene carácter disciplinario por los hechos ilícitos cometidos en el ejercicio específico de las funciones de las altas autoridades del... Tribunal Constitucional Plurinacional...", el cual si se encuentra probado da lugar a la destitución.

36 Así, el enjuiciamiento de tres magistrados del Tribunal Constitucional Plurinacional por emitir el AC 0106/2014-CA, 13 de marzo de 2014, de que en una acción de inconstitucionalidad abstracta suspendió la aplicación de la Ley del Notariado Plurinacional; en este sentido, la resolución de una de las magistradas sostuvo: "Se dispone la destitución definitiva de la sumariada Soraida Chanez Chire del cargo de magistrada del Tribunal Constitucional Plurinacional, debiendo en consecuencia... poner en conocimiento del Tribunal Supremo Electoral y del Tribunal Constitucional Plurinacional, habiéndose detectado elementos de condición sobre hechos ilícitos conforme lo previsto por el artículo 45, parágrafo 1, de la Ley 044 del 8 de octubre de 2010".

37 Santiago Salame, Fatma Yamila, "Juicio de responsabilidades a altos magistrados del órgano judicial: entre el juicio político y el penal”, La Jurídica. Revista Boliviana de Derecho Nacional e Internacional, La Paz, Bolivia, El Original San José, 2011. 
cionalidad, es decir, las normas emergentes del órgano legislativo pueden controlarse por el Tribunal Constitucional Plurinacional, pero la sentencia constitucional que declare la inconstitucionalidad de una ley a su vez puede ser controlada por el mismo órgano legislativo a través de un juicio de responsabilidades. ${ }^{38}$

Entonces, la existencia de un criterio mayoritario en la Asamblea Legislativa Plurinacional ${ }^{39}$ podría frustrar el control de constitucionalidad y limitar el derecho de las partes procesales a tener un juez independiente, en la medida en la que en el órgano legislativo existan los votos suficientes para no permitir una decisión jurisdiccional contramayoritaria o impopular, aspecto que si llegara a pasar podría provocar que la existencia del órgano de control de constitucionalidad deje de tener sentido porque sólo existiría para consagrar e imponer las decisiones legislativas a la minoría o a la oposición, y no para ejercer un verdadero control de constitucionalidad, ${ }^{40}$ de ahí que para evitar una situación semejante correspondería entregar el enjuiciamiento de los magistrados del Tribunal Constitucional Plurinacional al órgano judicial.

Por otra parte, tal vez esta posición preferente del órgano legislativo sobre el órgano de control de constitucionalidad pueda explicar el poco diálogo institucional entre ambas instituciones, por ejemplo respecto a las exhortaciones de la sentencias constitucionales; así, la SC 0024/2004-R de 16 de marzo, declaró la constitucionalidad del Código Civil "con vigencia temporal de cinco años a partir de la citación con la Sentencia..." por no haber emergido del órgano legislativo, sino del órgano ejecutivo

38 Se lesionaría la garantía de la vía judicial y el derecho al juez natural y, por ende, a la garantía del debido proceso.

39 Piénsese por ejemplo en la existencia de un partido político con mayoría parlamentaria.

40 A decir de Juan Carlos Bayón respecto a la importancia de la protección de derechos, se tiene que: "Parece mucho más atinado entender, por el contrario, que al menos algunos derechos y libertades individuales son en realidad prerrequisitos o condiciones necesarias de la genuina democracia, puesto que sin ellos el procedimiento de decisión por mayoría no diferiría realmente de la toma de decisiones manipuladas o impuestas, con lo que ni cabría afirmar que encarna verdaderamente el ideal que pretende hacer operativo (el de la auténtica participación de todos y en pie de igualdad en la toma de decisiones públicas) ni, en definitiva, habría por qué considerarlo valioso". Bayón, Juan Carlos, "Democracia y derechos: problemas de fundamentación del constitucionalismo", en Carbonell, Miguel y García Jaramillo, Leonardo (eds.), El canon neoconstitucional, Colombia, Universidad Externado, 2010. 
vulnerando el procedimiento legislativo establecido en la Constitución, por lo cual se:

EXHORTA al Poder Legislativo para que en dicho plazo subsane los vicios de origen de la indicada disposición legal, bajo conminatoria de que en caso de incumplimiento, la misma quedará expulsada del ordenamiento jurídico nacional al vencimiento del término antes señalado...

Plazo que venció en la gestión 2009, por lo que en la SCP 2139/2012 de 8 de noviembre de 2012, el órgano de control de constitucionalidad nuevamente amplió a otros cinco años la vigencia de la norma volviendo a realizar una exhortación similar a la anteriormente referida, aspecto que evidencia que el órgano legislativo no tomó con la suficiente seriedad la decisión del Tribunal Constitucional Plurinacional. ${ }^{41}$

Finalmente cabe dejar una reflexión sobre la redistribución de competencias en Bolivia a partir del reconocimiento de las sentencias de cortes internacionales de derechos humanos, en sentido de que a la Corte Interamericana de Derechos Humanos no le es obligatoria una sentencia constitucional, pues el Tribunal Constitucional Plurinacional es el máximo intérprete de derecho interno pero no del derecho internacional, de forma que una decisión constitucional que resuelve sobre derechos y garantías es todavía cuestionable ante dicha instancia internacional, ${ }^{42}$ por ello si bien nuestra Constitución establece que: "Las decisiones y sentencias del Tribunal Constitucional Plurinacional son de carácter vinculante y de cumplimiento obligatorio, y contra ellas no cabe recurso ordinario ulterior alguno", es posible puedan revisarse por la jurisdicción contenciosa de la referida Corte. ${ }^{43}$

41 Algo similar sucedió con el Decreto Ley 7755 denominado Ley del Servicio Nacional de Defensa que por SC 0007/2006 de 31 de enero, se declaró inconstitucional en la forma difiriéndose el efecto de la decisión por años y al mismo tiempo exhortándose al Legislativo para que: "en dicho plazo subsane los vicios de origen de la indicada disposición legal...”, lo que tampoco se produjo.

42 El Tribunal Constitucional Plurinacional de Bolivia es el último intérprete de la Constitución en su parte orgánica, es decir en lo referido a la organización estatal, pero no en su parte dogmática, en la regulación de derechos, pues en este último caso es posible impugnar la decisión, por ejemplo, ante el sistema interamericano de protección de derechos humanos.

43 Por ejemplo, en el caso Castillo Petruzzi y otros vs. Perú, de la Corte Interamericana de Derechos Humanos, se determinó: “...declara la invalidez, por ser incompatible 


\section{A MODO DE CONCLUSIÓN}

La relación entre el órgano legislativo y el órgano de control de constitucionalidad se basa en la búsqueda por constituirse en el máximo intérprete de la Constitución, es decir, en la pugna por tener la palabra final en la determinación del contenido de los mandatos de la norma suprema y que ésta sea a través de leyes o de sentencias constitucionales, disputa que en definitiva se determinará por el contexto histórico, social, político, económico, etcétera. Así, el margen de interpretación de los tribunales constitucionales puede aumentarse o reducirse como consecuencia del grado de deslegitimación de la labor de los congresos y parlamentos, situación que propicia el activismo judicial.

La existencia de un control de poder recíproco implica que previamente hay una distribución de competencias y límites en la actuación de los órganos de poder establecido en la Constitución, lo contrario provocaría que no haya nada que controlar.

Como se puede observar, en Bolivia la facultad de juzgamiento de la Asamblea Legislativa Plurinacional a los miembros del Tribunal Constitucional Plurinacional por las resoluciones que emita $-v$. $g r$. declarando la inconstitucionalidad de una ley - se contrapone a la idea del control recíproco, pues si el órgano controlado puede luego controlar al controlador, lógicamente el segundo, por razones prudenciales, tenderá a la autorrestricción, lo que frustrará el diálogo institucional entre ambas instancias, pero además pondrá en duda a la propia noción de supremacía constitucional en la medida en que se dificultaría a la minoría desafiar a las mayorías parlamentarias. $^{44}$

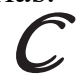

con la Convención Americana sobre Derechos Humanos, del proceso en contra de los señores Jaime Francisco Sebastián Castillo Petruzzi, María Concepción Pincheira Sáez, Lautaro Enrique Mellado Saavedra y Alejandro Luis Astorga Valdez y ordena que se les garantice un nuevo juicio con la plena observancia del debido proceso legal".

44 "Cuando en una determinada coyuntura, no existe materialmente una separación entre Poder Ejecutivo y el Poder Judicial, no se puede hablar de un procedimiento judicial propio de una administración de justicia, sino de un procedimiento de guerra", Zárate, Alan, Derecho penal del enemigo en la legislación boliviana, Bolivia, El Original San José, 2014, p. 64.

Fecha de recepción: 4 de julio de 2017.

Fecha de dictamen: 13 de diciembre de 2017. 